\title{
A Novel Evaluation Method for Building Construction Project Based on Integrated Information Entropy with Reliability Theory
}

\author{
Xiao-ping Bai and Xi-wei Zhang \\ School of Management, Xian University of Architecture and Technology, Xian Shanxi 710055, China \\ Correspondence should be addressed to Xiao-ping Bai; xxppbai@163.com
}

Received 8 January 2013; Accepted 28 January 2013

Academic Editors: D. Choudhury and Z. Guan

Copyright (C) 2013 X.-p. Bai and X.-w. Zhang. This is an open access article distributed under the Creative Commons Attribution License, which permits unrestricted use, distribution, and reproduction in any medium, provided the original work is properly cited.

\begin{abstract}
Selecting construction schemes of the building engineering project is a complex multiobjective optimization decision process, in which many indexes need to be selected to find the optimum scheme. Aiming at this problem, this paper selects cost, progress, quality, and safety as the four first-order evaluation indexes, uses the quantitative method for the cost index, uses integrated qualitative and quantitative methodologies for progress, quality, and safety indexes, and integrates engineering economics, reliability theories, and information entropy theory to present a new evaluation method for building construction project. Combined with a practical case, this paper also presents detailed computing processes and steps, including selecting all order indexes, establishing the index matrix, computing score values of all order indexes, computing the synthesis score, sorting all selected schemes, and making analysis and decision. Presented method can offer valuable references for risk computing of building construction projects.
\end{abstract}

\section{Introduction}

The evaluation decision of building construction schemes is a complex multiobjective and multifactor problem, selecting a reasonable goal structure system of evaluation schemes and the optimal scheme is very important in the building construction decision process [1].

Until now, there have been many references studying the optimization decision problem of building construction schemes, and many concepts about it have been set up. Among them, some research results only aim at the small range special field; for example, some researchers study pit bracing construction scheme decision problem [2]. Analytical Hierarchy Process (AHP) is a common method; however, its convictive power is not strong enough because it lacks quantitative data analysis [3-5]. In [6], authors integrated value engineering principle with technical and economic factors to make evaluating and decision making of construction schemes, its advantage is more considering evaluation factors included in construction schemes, but the selection of evaluation values is fuzzy [6]. In addition, grey correlation
[7], minimum variance [8], fuzzy decision, projection pursuit, and other methods are also used in decision-making of project schemes $[9,10]$.

The optimization decision-making evaluation of construction schemes is a multiobjective process; many targets should be analyzed. Some references select cost, progress, quality, and reliability as evaluation targets, such as in [11, 12], analysis of time-cost-quality tradeoff optimization in construction project management is presented [11,12], but on the whole there is a shortage of systematic deep discussion, and qualitative study is dominant.

Reliability method is rarely used in the decision making of construction schemes, which is usually simply mentioned in three elements of the project in management references. In [13], reliability method is applied in the evaluation of the construction procedure [13].

In multiobjective optimization decision-making evaluation of projects, the relatively important degree of each evaluation index usually should be considered. The most direct and simple method expressing the important degree of each evaluation target is to give each target relevant weight. The 
TABLE 1: The detailed composition of building construction cost.

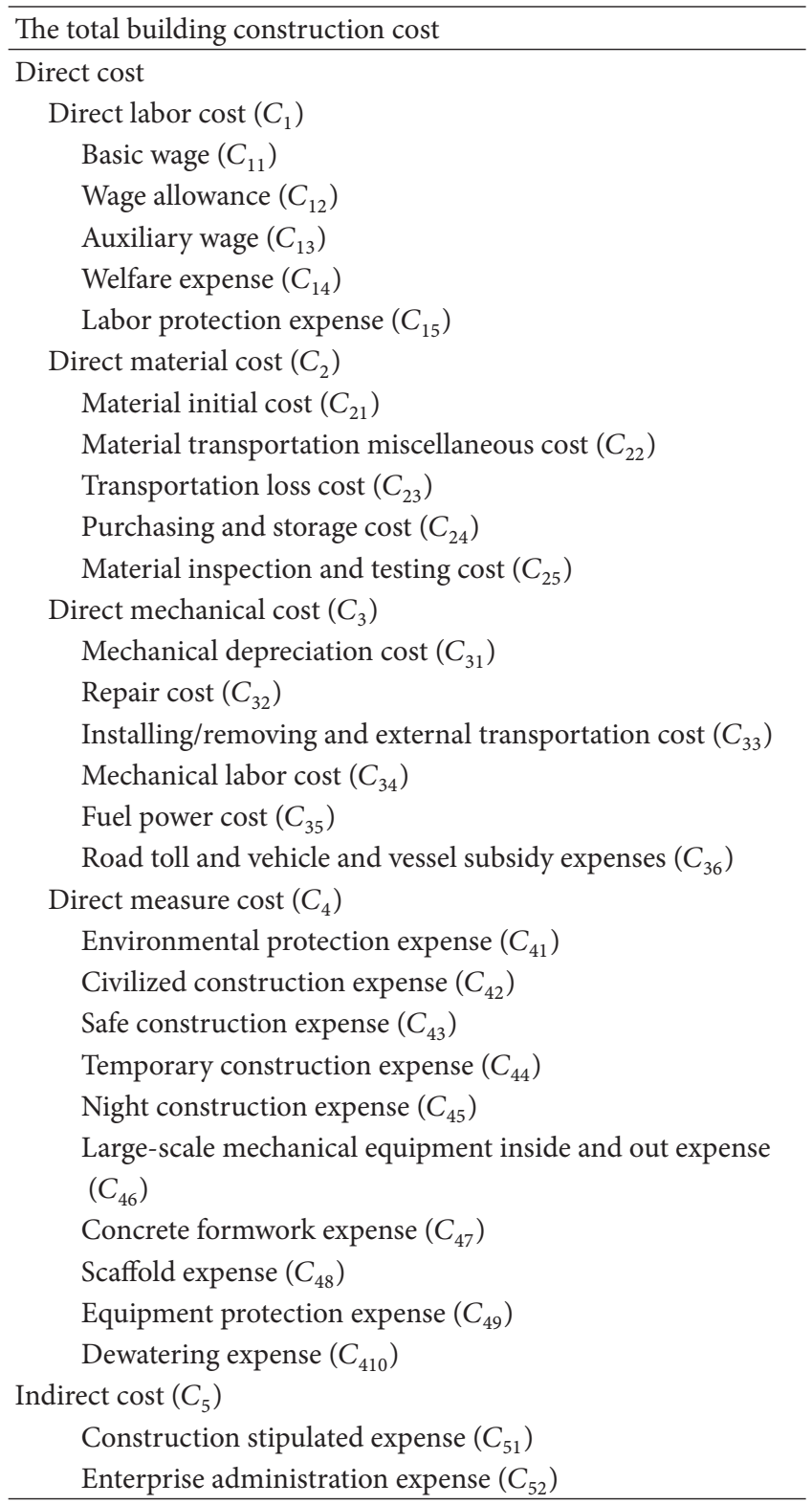

entropy is a very ideal criterion to be applied for evaluating different decision-making processes. Applying the entropy principle to determine the weights of evaluation indexes has the scientific and the accuracy nature. In 1991, two Chinese scholars GU Changyao and QIU Wanhua firstly defined complex entropy and apply it in decision analysis. In 1994, QIU Wanhua also presents group decision-making complex entropy model [14].

In [15], the authors presented the evolution of concepts, an overview of research and applications pertaining to reliability in construction production, and the use of reserves, robust itineraries, and contingency of time and cost. It describes areas of management advisory systems in relation to the cycle of risk analysis [15].

In [16], a biobjective genetic algorithm was employed to solve the multiperiod network optimization problem, and a

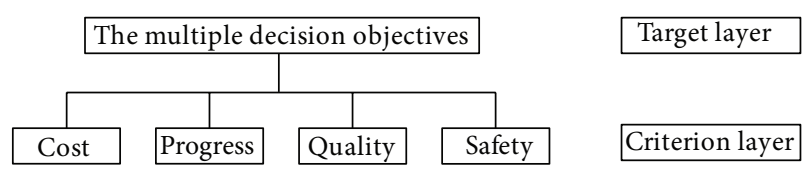

FIgURE 1: The multiobjective evaluation chart of building project construction schemes.

numerical example shows that the optimal coordination saves more than $50 \%$ of waste in system costs, compared to the worst-case scenario [16].

Making use of many existed studying results, this paper integrates engineering economics, risk and reliability theories, and information entropy theory to present a set of detailed engineering management decision methods of building construction projects combined with the concrete example. Presented detailed methods and steps can offer the reference for engineering management decision of building construction projects.

On the basis of summarizing and absorbing some existed references, this paper selected engineering cost, progress, quality, and safety as first-order criterion indexes, shown in Figure 1. For every first-order criterion index, further extended analysis calculation was done.

\section{Calculating Cost of Building Construction Schemes}

Combined with practical engineering experiences, the building construction cost of engineering projects includes direct cost and indirect cost. The direct cost also includes direct labor cost $\left(C_{1}\right)$, direct material cost $\left(C_{2}\right)$, direct mechanical cost $\left(C_{3}\right)$, and direct measure cost $\left(C_{4}\right)$. The indirect cost $\left(C_{5}\right)$ includes building construction stipulated expense and enterprise administration expense. The detail composition of building construction cost can be expressed by Table 1 .

The total building construction cost can be calculated by

$$
C=C_{1}+C_{2}+C_{3}+C_{4}+C_{5} .
$$

\section{Calculating the Progress Score Value of Building Construction Schemes Combined with Reliability Theory}

Combined with practical engineering experiences, this paper divided the whole building construction project engineering into 10 first-order progress segments; moreover, the firstorder progress segment is divided into detailed second-order progress segments, as shown in Table 2. The progress score value of every second-order progress segment can be given out directly by domain experts.

The total progress score value can be calculated by

$$
R=\sum_{i=1}^{10} R_{i}
$$

where $R_{i}$ is the sum of progress score value of the $i$ first-order progress segment. 
TABLE 2: The detailed segment composition of building construction progress.

First-order progress influence factor segments

\begin{tabular}{|c|c|c|}
\hline \multirow{7}{*}{ Site leveling progress $\left(T_{1}\right)$} & Scene investigation progress $\left(T_{11}\right)$ & $R_{11}$ \\
\hline & Removing obstacle progress $\left(T_{12}\right)$ & $R_{12}$ \\
\hline & Calibrating range, setting benchmarks, and grid progress $\left(T_{13}\right)$ & $R_{13}$ \\
\hline & Measuring elevation progress $\left(T_{14}\right)$ & $R_{14}$ \\
\hline & Calculating earthwork cut and fill engineering quantities progress $\left(T_{15}\right)$ & $R_{15}$ \\
\hline & Land leveling progress $\left(T_{16}\right)$ & $R_{16}$ \\
\hline & Field compaction progress $\left(T_{17}\right)$ & $R_{17}$ \\
\hline \multirow{6}{*}{ Ground foundation progress $\left(T_{2}\right)$} & Earth excavation progress $\left(T_{21}\right)$ & $R_{21}$ \\
\hline & Cushion placement progress $\left(T_{22}\right)$ & $R_{22}$ \\
\hline & Foundation placement progress $\left(T_{23}\right)$ & $R_{23}$ \\
\hline & Foundation wall placement progress $\left(T_{24}\right)$ & $R_{24}$ \\
\hline & Base pillar, ground ring beam progress $\left(T_{25}\right)$ & $R_{25}$ \\
\hline & Backfilling earthwork progress $\left(T_{26}\right)$ & $R_{26}$ \\
\hline \multirow{4}{*}{ Body engineering progress $\left(T_{3}\right)$} & Reinforcement engineering progress $\left(T_{31}\right)$ & $R_{31}$ \\
\hline & Formwork engineering progress $\left(T_{32}\right)$ & $R_{32}$ \\
\hline & Concrete engineering progress $\left(T_{33}\right)$ & $R_{33}$ \\
\hline & Masonry engineering progress $\left(T_{34}\right)$ & $R_{34}$ \\
\hline \multirow{5}{*}{ Roof engineering progress $\left(T_{4}\right)$} & Clean up, leveling progress $\left(T_{41}\right)$ & $R_{41}$ \\
\hline & Processing insulation layer progress $\left(T_{42}\right)$ & $R_{42}$ \\
\hline & Waterproofing and drainage progress $\left(T_{43}\right)$ & $R_{43}$ \\
\hline & Setting qualified seaming progress $\left(T_{44}\right)$ & $R_{44}$ \\
\hline & Ventilation, exhaust progress $\left(T_{45}\right)$ & $R_{45}$ \\
\hline \multirow{5}{*}{ Decoration and fitment progress $\left(T_{5}\right)$} & Groundwater seepage test of bathroom and kitchen progress $\left(T_{51}\right)$ & $R_{51}$ \\
\hline & Laying chisel trough and circuit pipeline progress $\left(T_{52}\right)$ & $R_{52}$ \\
\hline & Sealing and burying trunk progress $\left(T_{53}\right)$ & $R_{53}$ \\
\hline & Decoration and fitment progress of public wall $\left(T_{54}\right)$ & $R_{54}$ \\
\hline & Installing doors and windows progress $\left(T_{55}\right)$ & $R_{55}$ \\
\hline \multirow{4}{*}{$\begin{array}{l}\text { Water, electricity, and HVAC progress } \\
\left(T_{6}\right)\end{array}$} & Water supply and sewerage progress $\left(T_{61}\right)$ & $R_{61}$ \\
\hline & Laying circuit progress $\left(T_{62}\right)$ & $R_{62}$ \\
\hline & Installing heating progress $\left(T_{63}\right)$ & $R_{63}$ \\
\hline & Water, heating, and electrical test progress $\left(T_{64}\right)$ & $R_{64}$ \\
\hline \multirow{3}{*}{ Equipment installation progress $\left(T_{7}\right)$} & Installing elevator progress $\left(T_{71}\right)$ & $R_{71}$ \\
\hline & Installing fire-fighting equipment progress $\left(T_{72}\right)$ & $R_{72}$ \\
\hline & Installing emergency device progress $\left(T_{73}\right)$ & $R_{73}$ \\
\hline \multirow{3}{*}{ Goods transportation progress $\left(T_{8}\right)$} & Goods transportation scheme 1 progress $\left(T_{81}\right)$ & $R_{81}$ \\
\hline & Goods transportation scheme 2 progress $\left(T_{82}\right)$ & $R_{82}$ \\
\hline & Goods transportation scheme 3 progress $\left(T_{83}\right)$ & $R_{83}$ \\
\hline \multirow{2}{*}{ Environmental factor progress $\left(T_{9}\right)$} & Natural environment factor progress $\left(T_{91}\right)$ & $R_{91}$ \\
\hline & Social environment factor progress $\left(T_{92}\right)$ & $R_{92}$ \\
\hline \multirow{5}{*}{ Other factors progress $\left(T_{10}\right)$} & Construction design drawings change progress $\left(T_{101}\right)$ & $R_{101}$ \\
\hline & Construction machinery, materials changes progress $\left(T_{102}\right)$ & $R_{102}$ \\
\hline & Progress affected by weak supervision $\left(T_{103}\right)$ & $R_{103}$ \\
\hline & Progress affected by supply failure of the municipal system $\left(T_{104}\right)$ & $R_{104}$ \\
\hline & Progress affected by great political and social activities $\left(T_{105}\right)$ & $R_{105}$ \\
\hline
\end{tabular}

Second-order progress influence factor segments

Progress score value

\section{Construction progress} . 
TABLE 3: The detailed quality influence factor segment composition of the building construction schemes.

\begin{tabular}{|c|c|c|}
\hline \multicolumn{3}{|c|}{ Engineering quality } \\
\hline $\begin{array}{l}\text { First-order influence quality factor } \\
\text { segments }\end{array}$ & Second-order influence quality factor segments & Quality score value \\
\hline \multirow{4}{*}{ Site leveling quality segment $\left(Q_{1}\right)$} & Machinery performance influence quality segment $\left(Q_{11}\right)$ & $A_{11}$ \\
\hline & Measuring tool influence quality segment $\left(Q_{12}\right)$ & $A_{12}$ \\
\hline & Climate influence quality segment $\left(Q_{13}\right)$ & $A_{13}$ \\
\hline & Worker influence quality segment $\left(Q_{14}\right)$ & $A_{14}$ \\
\hline \multirow{7}{*}{$\begin{array}{l}\text { Ground and foundation quality } \\
\text { segment }\left(Q_{2}\right)\end{array}$} & Equipment performance influence quality segment $\left(Q_{21}\right)$ & $A_{21}$ \\
\hline & Materials reliability influence quality segment $\left(Q_{22}\right)$ & $A_{22}$ \\
\hline & Personnel quality influence quality segment $\left(Q_{23}\right)$ & $A_{23}$ \\
\hline & Drawings reliability influence quality segment $\left(Q_{24}\right)$ & $A_{24}$ \\
\hline & Construction plans influence quality segment $\left(Q_{25}\right)$ & $A_{25}$ \\
\hline & Construction technology influence quality segment $\left(Q_{26}\right)$ & $A_{26}$ \\
\hline & Construction environment influence quality segment $\left(Q_{27}\right)$ & $A_{27}$ \\
\hline \multirow{7}{*}{$\begin{array}{l}\text { Main body engineering quality } \\
\text { segment }\left(Q_{3}\right)\end{array}$} & Construction machinery influence quality segment $\left(Q_{31}\right)$ & $A_{31}$ \\
\hline & Construction technology influence quality segment $\left(Q_{32}\right)$ & $A_{32}$ \\
\hline & Manager's quality influence quality segment $\left(Q_{33}\right)$ & $A_{33}$ \\
\hline & Construction technique maturation influence quality segment $\left(Q_{34}\right)$ & $A_{34}$ \\
\hline & Construction materials influence quality segment $\left(Q_{35}\right)$ & $A_{35}$ \\
\hline & Construction worker technology influence quality segment $\left(Q_{36}\right)$ & $A_{36}$ \\
\hline & Construction drawing reliability influence quality segment $\left(Q_{37}\right)$ & $A_{37}$ \\
\hline \multirow{4}{*}{$\begin{array}{l}\text { Decoration and fitment engineering } \\
\text { quality segment }\left(Q_{4}\right)\end{array}$} & Decoration and fitment material influence quality segment $\left(Q_{41}\right)$ & $A_{41}$ \\
\hline & Construction worker influence quality segment $\left(Q_{42}\right)$ & $A_{42}$ \\
\hline & Constructor influence quality segment $\left(Q_{43}\right)$ & $A_{43}$ \\
\hline & Construction equipment influence quality segment $\left(Q_{44}\right)$ & $A_{44}$ \\
\hline \multirow{3}{*}{ Building roof quality segment $\left(Q_{5}\right)$} & $\begin{array}{l}\text { Waterproof and thermal insulation material reliability influence } \\
\text { quality segment }\left(Q_{51}\right)\end{array}$ & $A_{51}$ \\
\hline & $\begin{array}{l}\text { Construction technology and procedure influence quality segment } \\
\left(Q_{52}\right)\end{array}$ & $A_{52}$ \\
\hline & Working environment influence quality segment $\left(Q_{53}\right)$ & $A_{53}$ \\
\hline \multirow{3}{*}{$\begin{array}{l}\text { Building water supply and drainage, } \\
\text { heating quality segment }\left(Q_{6}\right)\end{array}$} & $\begin{array}{l}\text { Water supply and drainage, heating ventilating pipe influence quality } \\
\text { segment }\left(Q_{61}\right)\end{array}$ & $A_{61}$ \\
\hline & Constructor technology level influence quality segment $\left(Q_{62}\right)$ & $A_{62}$ \\
\hline & Construction technology influence quality segment $\left(Q_{63}\right)$ & $A_{63}$ \\
\hline \multirow{2}{*}{$\begin{array}{l}\text { Building equipment and installation } \\
\text { quality segment }\left(Q_{7}\right)\end{array}$} & Equipment reliability influence quality segment $\left(Q_{71}\right)$ & $A_{71}$ \\
\hline & Professional technology constructor influence quality segment $\left(Q_{71}\right)$ & $A_{72}$ \\
\hline
\end{tabular}

TABLE 4: The detailed composition of building construction safety influence factor.

\begin{tabular}{lll}
\hline Human safety factor $\left(S_{1}\right)$ & Matter safety factor $\left(S_{2}\right)$ & Environment safety factor $\left(S_{3}\right)$ \\
\hline $\begin{array}{l}\text { Not wearing security protection } \\
\text { apparatus }\left(S_{11}\right)\end{array}$ & Not setting safety protection $\left(S_{21}\right)$ & Construction natural conditions $\left(S_{31}\right)$ \\
Unsafe costume $\left(S_{12}\right)$ & Incorrect safety protection and dice marking $\left(S_{22}\right)$ & Narrow construction work surface $\left(S_{32}\right)$ \\
Wrong mechanical operation $\left(S_{13}\right)$ & Mechanical equipment being in the unsafe state $\left(S_{23}\right)$ & Disorderly construction yard $\left(S_{33}\right)$ \\
Ignoring safety warning $\left(S_{14}\right)$ & Mechanical equipment being in nonnormal state $\left(S_{24}\right)$ & Artificial lighting in the night is lacking $\left(S_{34}\right)$ \\
Using unsafe equipment $\left(S_{15}\right)$ & The material stacked in the unsafe state $\left(S_{25}\right)$ & Wrong operation process design $\left(S_{35}\right)$ \\
$\begin{array}{l}\text { Body or spirit reason }\left(S_{16}\right) \\
\text { Rash advance operation }\left(S_{17}\right)\end{array}$ & Having harmful material $\left(S_{26}\right)$ & Bad ventilation $\left(S_{36}\right)$ \\
$\begin{array}{l}\text { Being in unsafe site }\left(S_{18}\right) \\
\text { Error handling of dangerous goods }\end{array}$ & & Improper protection for traffic line $\left(S_{37}\right)$ \\
$\left(S_{19}\right)$ & & \\
\hline
\end{tabular}


TABle 5: Taking value of three risk degree indexes.

\begin{tabular}{|c|c|c|c|c|c|}
\hline \multicolumn{2}{|l|}{ Possibility } & \multicolumn{2}{|l|}{ Probability } & \multicolumn{2}{|l|}{ Result } \\
\hline Caused accident possibility & $\begin{array}{l}\text { Taking the } \\
\text { value of } M\end{array}$ & Caused accident probability & $\begin{array}{l}\text { Taking the } \\
\text { value of } P\end{array}$ & The result caused by accident & $\begin{array}{l}\text { Taking the } \\
\text { value of } F\end{array}$ \\
\hline Sustainably occur & 10 & Very large possible occurrence & 10 & $\begin{array}{l}\text { Extreme large accident, shutdown, } \\
\text { and rectification }\end{array}$ & 10 \\
\hline Often occur & 8 & Large possible occurrence & 8 & Very large accident, causing death & 9 \\
\hline Occur for many times & 6 & Possible occurrence & 6 & $\begin{array}{l}\text { Severe accident, having severe } \\
\text { injury }\end{array}$ & 7 \\
\hline Occur in a few times & 5 & Occur for once a while & 5 & Accident, having slight injury & 5 \\
\hline Occur for very few times & 3 & Rare occurrence & 3 & $\begin{array}{l}\text { Small accident, having minor } \\
\text { injures }\end{array}$ & 3 \\
\hline Basically not occur & 1 & Basically impossible & 1 & Very small accident, no injury & 1 \\
\hline
\end{tabular}

TABLE 6: The calculated cost value of 4 construction schemes (unit: ten thousand yuan).

\begin{tabular}{lccccc}
\hline & $C_{1}$ & $C_{2}$ & $C_{3}$ & $C_{4}$ & $C_{5}$ \\
\hline Scheme 1 & 89.70 & 110.85 & 69.80 & 13.52 & 22.71 \\
Scheme 2 & 76.80 & 121.90 & 73.75 & 13.62 & 22.89 \\
Scheme 3 & 81.45 & 115.37 & 60.15 & 12.85 & 21.59 \\
Scheme 4 & 79.45 & 118.69 & 70.23 & 13.42 & 22.54 \\
\hline
\end{tabular}

For calculating $R_{i}$, the authors make use of related knowledge in reliability theory. Considering that the progress relations of various second-order progress segments among goods transportation progress $\left(T_{8}\right)$ are parallel, so $R_{8}$ can be calculated by

$$
R_{8}=1-\left(1-R_{81}\right)\left(1-R_{82}\right)\left(1-R_{83}\right) .
$$

For other $R_{i}$ except for $R_{8}$, the progress relation of various second-order progress segments are a series, so $R_{i}$ except for $R_{8}$ can be calculated by

$$
R_{i}=\sum_{j=1}^{n_{i}} R_{i j},
$$

where $n_{i}$ is the number of second-order progress segments among the $i$ first-order progress segment.

\section{Calculating Quality Score Value of Building Construction Schemes Combined with Reliability Theory}

The authors divide the whole building construction project engineering into 7 first-order influence quality factor segments. Every first-order influence quality factor segment is divided into detailed second-order segments, as shown in Table 3.

For calculating the quality score value of every secondorder influence quality factor segment, this paper divides them into two types; one type can be calculated by related reliability method, including collecting failure data, putting forward hypotheses by the frequency histogram, estimating parameters, and testing hypothesis. The other type can be calculated by the expert evaluation method.

Combined with practical engineering knowledge, the quality relations of various second-order quality segments included in every first-order quality segment are a series, so the quality score value of every first-order quality segment can be calculated by

$$
A_{i}=\sum_{j=1}^{n_{i}} A_{i j}
$$

where $n_{i}$ is the number of second-order quality segments among the $i$ first-order quality segment.

The total quality score value can be calculated by

$$
A=\sum_{i=1}^{7} A_{i} .
$$

\section{Calculating Safety Score Value of Building Construction Schemes}

Factors affecting building construction safety mainly include direct factor and indirect factor. Direct factors include human factor, matter factor, and environment factor; indirect factors include management factor, and it is caused by three direct factors. This paper further analyzes three direct factors; the detailed composition of building construction safety influence factor is shown in Table 4.

In this paper, the safety score value can be calculated by

$$
W_{i}=M_{i} \times P_{i} \times F_{i}
$$

where $M$ expresses the possibility risk degree index caused by unsafe factors in $i$ safety factor, $P$ expresses the probability risk degree index caused by $i$ unsafe factor, and $F$ expresses the produced result risk degree index after the accident in $i$ safety factor. The value of three indexes can be obtained by experts according to Table 5 .

The total quality score value can be calculated by

$$
W=\sum_{i=1}^{3} W_{i}
$$




\section{Case Studies and Synthesis Computational Method Based on Integrated Information Entropy with Reliability Theory}

6.1. Case Analysis. Taking a building construction engineering project, for example, it is located in the third ring road east section of a city outskirt, has convenient traffic environment. There are residential buildings on the east, west, and north sides of this project; a Greenbelt Park is located in the south side of it. The total land area is 15 acres, the plot ratio is 2.1, and it is planned to be completed in one stage. The building engineering construction will begin on March 1, 2013; the planned construction period is 12 months.

The construction scheme 1 is described as follows. The expected period of engineering construction is 12 months. The month construction completed rate of this scheme, respectively, is $8 \%, 10 \%, 11 \%, 10 \%, 8 \%, 8 \%, 10 \%, 11 \%, 8 \%, 6 \%$, $6 \%$, and $4 \%$. The month construction progresses in winter and summer is slower than other months because of the effects of the natural environment.

In construction scheme 2 , the expected period of engineering construction is 11 months. The month construction completed rate of this scheme, respectively, is $9 \%, 11 \%, 11 \%$, $11 \%, 9 \%, 9 \%, 12 \%, 11 \%, 8 \%, 8 \%$, and $7 \%$.

In construction scheme 3 , the expected period of engineering construction is 11 months. The month construction completed rate of this scheme, respectively, is $9 \%, 10 \%, 11 \%$, $10 \%, 9 \%, 8 \%, 10 \%, 10 \%, 8 \%, 7 \%, 6 \%$, and $2 \%$.

In construction scheme 4 , the expected period of engineering construction is 12 months. The month construction completed rate of this scheme, respectively, is $7 \%, 9 \%, 9 \%, 9 \%$, $8 \%, 8 \%, 10 \%, 10 \%, 9 \%, 8 \%, 7 \%$, and $6 \%$.

According to Table 1 and formula (1) to calculate, respectively, the cost of 4 construction schemes, the result is shown in Table 6.

According to Table 2, formula (2), (3), and (4) to calculate, respectively, progress score value of 4 building construction schemes, the result is shown in Table 7 .

According to Table 3, formula (5) and (6) to calculate, respectively, quality score value of 4 building construction schemes, the result is shown in Table 8 .

According to Tables 4 and 5, and formula (7) and (8) to calculate, respectively, safety score value of 4 building construction schemes, the result is shown in Table 9.

According to above detailed calculating methods and steps, the result is shown as a calculated total value of 4 indexes including cost, progress, quality, and safety of 4 building construction schemes, as shown in Table 10.

6.2. Detailed Computing Steps of Entropy Weight. Regarding a multiobjective decision making problem that has $m$ selected schemes and $n$ evaluation indexes, detailed computing steps of entropy weight are as follows.

(1) Establishe evaluation index matrix including each evaluation index and corresponding evaluation value:

$$
A=\left(a_{i j}\right)_{m \times n} \text {. }
$$

(2) Standardize evaluation index matrix.
TABLE 7: The calculated progress score value of 4 building construction schemes.

\begin{tabular}{|c|c|c|c|c|}
\hline & Scheme 1 & Scheme 2 & Scheme 3 & Scheme 4 \\
\hline$T_{11}$ & 0.98 & 0.96 & 0.98 & 0.97 \\
\hline$T_{12}$ & 0.92 & 0.93 & 0.94 & 0.95 \\
\hline$T_{13}$ & 0.97 & 0.95 & 0.86 & 0.95 \\
\hline$T_{14}$ & 0.87 & 0.86 & 0.92 & 0.98 \\
\hline$T_{15}$ & 0.99 & 0.87 & 0.95 & 0.95 \\
\hline$T_{16}$ & 0.96 & 0.91 & 0.89 & 0.88 \\
\hline$T_{17}$ & 0.89 & 0.97 & 0.97 & 0.93 \\
\hline$T_{21}$ & 0.95 & 0.94 & 0.97 & 0.94 \\
\hline$T_{22}$ & 0.92 & 0.98 & 0.86 & 0.89 \\
\hline$T_{23}$ & 0.93 & 0.91 & 0.94 & 0.93 \\
\hline$T_{24}$ & 0.99 & 0.98 & 0.89 & 0.92 \\
\hline$T_{25}$ & 0.98 & 0.92 & 0.99 & 0.89 \\
\hline$T_{26}$ & 0.88 & 0.97 & 0.97 & 0.99 \\
\hline$T_{31}$ & 0.98 & 0.87 & 0.95 & 0.91 \\
\hline$T_{32}$ & 0.94 & 0.95 & 0.92 & 0.98 \\
\hline$T_{33}$ & 0.97 & 0.88 & 0.92 & 0.87 \\
\hline$T_{34}$ & 0.91 & 0.86 & 0.94 & 0.87 \\
\hline$T_{41}$ & 0.89 & 0.91 & 0.91 & 0.92 \\
\hline$T_{42}$ & 0.92 & 0.87 & 0.96 & 0.98 \\
\hline$T_{43}$ & 0.89 & 0.89 & 0.88 & 0.96 \\
\hline$T_{44}$ & 0.92 & 0.94 & 0.91 & 0.87 \\
\hline$T_{45}$ & 0.97 & 0.85 & 0.90 & 0.96 \\
\hline$T_{51}$ & 0.88 & 0.98 & 0.94 & 0.87 \\
\hline$T_{52}$ & 0.85 & 0.91 & 0.87 & 0.91 \\
\hline$T_{53}$ & 0.98 & 0.94 & 0.86 & 0.92 \\
\hline$T_{54}$ & 0.89 & 0.95 & 0.86 & 0.86 \\
\hline$T_{55}$ & 0.99 & 0.91 & 0.91 & 0.92 \\
\hline$T_{61}$ & 0.86 & 0.88 & 0.87 & 0.96 \\
\hline$T_{62}$ & 0.98 & 0.96 & 0.89 & 0.98 \\
\hline$T_{63}$ & 0.92 & 0.88 & 0.90 & 0.92 \\
\hline$T_{64}$ & 0.91 & 0.91 & 0.90 & 0.95 \\
\hline$T_{71}$ & 0.90 & 0.93 & 0.88 & 0.95 \\
\hline$T_{72}$ & 0.88 & 0.95 & 0.91 & 0.94 \\
\hline$T_{73}$ & 0.92 & 0.86 & 0.90 & 0.85 \\
\hline$T_{81}$ & 0.89 & 0.91 & 0.91 & 0.85 \\
\hline$T_{82}$ & 0.92 & 0.88 & 0.94 & 0.88 \\
\hline$T_{83}$ & 0.88 & 0.90 & 0.86 & 0.96 \\
\hline$T_{91}$ & 0.86 & 0.93 & 0.96 & 0.99 \\
\hline$T_{92}$ & 0.89 & 0.95 & 0.95 & 0.86 \\
\hline$T_{101}$ & 0.89 & 0.87 & 0.96 & 0.88 \\
\hline$T_{102}$ & 0.85 & 0.85 & 0.89 & 0.98 \\
\hline$T_{103}$ & 0.93 & 0.94 & 0.98 & 0.91 \\
\hline$T_{104}$ & 0.94 & 0.97 & 0.91 & 0.89 \\
\hline$T_{105}$ & 0.98 & 0.88 & 0.93 & 0.86 \\
\hline
\end{tabular}

For the index that is "the bigger, the better," the standardized value $r_{i j}$ of the evaluation index can be calculated by

$$
r_{i j}=\frac{a_{i j}-\min a_{i j}}{\max a_{i j}-\min a_{i j}} .
$$


TABLE 8: The calculated quality score value of 4 building construction schemes.

\begin{tabular}{|c|c|c|c|c|}
\hline & Scheme 1 & Scheme 2 & Scheme 3 & Scheme 4 \\
\hline$Q_{11}$ & 0.97 & 0.92 & 0.96 & 0.90 \\
\hline$Q_{12}$ & 0.93 & 0.91 & 0.98 & 0.93 \\
\hline$Q_{13}$ & 0.99 & 0.91 & 0.97 & 0.96 \\
\hline$Q_{14}$ & 0.92 & 0.94 & 0.98 & 0.96 \\
\hline$Q_{21}$ & 0.93 & 0.97 & 0.97 & 0.98 \\
\hline$Q_{22}$ & 0.95 & 0.93 & 0.94 & 0.99 \\
\hline$Q_{23}$ & 0.94 & 0.99 & 0.91 & 0.93 \\
\hline$Q_{24}$ & 0.91 & 0.97 & 0.96 & 0.92 \\
\hline$Q_{25}$ & 0.91 & 0.94 & 0.96 & 0.96 \\
\hline$Q_{26}$ & 0.94 & 0.96 & 0.96 & 0.98 \\
\hline$Q_{27}$ & 0.92 & 0.97 & 0.93 & 0.90 \\
\hline$Q_{31}$ & 0.98 & 0.97 & 0.97 & 0.91 \\
\hline$Q_{32}$ & 0.91 & 0.98 & 0.92 & 0.92 \\
\hline$Q_{33}$ & 0.95 & 0.90 & 0.97 & 0.93 \\
\hline$Q_{34}$ & 0.92 & 0.92 & 0.91 & 0.97 \\
\hline$Q_{35}$ & 0.95 & 0.91 & 0.91 & 0.97 \\
\hline$Q_{36}$ & 0.91 & 0.96 & 0.96 & 0.90 \\
\hline$Q_{37}$ & 0.95 & 0.93 & 0.98 & 0.95 \\
\hline$Q_{41}$ & 0.94 & 0.98 & 0.98 & 0.92 \\
\hline$Q_{42}$ & 0.92 & 0.97 & 0.97 & 0.93 \\
\hline$Q_{43}$ & 0.92 & 0.94 & 0.98 & 0.95 \\
\hline$Q_{44}$ & 0.93 & 0.94 & 0.93 & 0.96 \\
\hline$Q_{51}$ & 0.90 & 0.92 & 0.91 & 0.94 \\
\hline$Q_{52}$ & 0.96 & 0.96 & 0.95 & 0.91 \\
\hline$Q_{53}$ & 0.94 & 0.98 & 0.96 & 0.96 \\
\hline$Q_{61}$ & 0.97 & 0.94 & 0.91 & 0.93 \\
\hline$Q_{62}$ & 0.90 & 0.94 & 0.92 & 0.97 \\
\hline$Q_{63}$ & 0.96 & 0.98 & 0.96 & 0.94 \\
\hline$Q_{71}$ & 0.92 & 0.92 & 0.93 & 0.98 \\
\hline$Q_{72}$ & 0.90 & 0.93 & 0.92 & 0.94 \\
\hline
\end{tabular}

For the index that is "the smaller, the better," the standardized value $r_{i j}$ of the evaluation index can be calculated by

$$
r_{i j}=\frac{\max a_{i j}-a_{i j}}{\max a_{i j}-\min a_{i j}} .
$$

So the standardized decision-making matrix $\left(R=\left(r_{i j}\right)_{m \times n}\right.$, $\left.r_{i j} \in[0,1]\right)$ can be obtained.

(3) Calculate the entropy value of each evaluation index:

$$
\begin{aligned}
H_{j}= & -k \sum_{i=1}^{m} f_{i j} \ln f_{i j} \quad(j=1, \ldots, n) \\
& \times\left(f_{i j}=\frac{r_{i j}}{\left(\sum_{i=1}^{m} r_{i j}\right)}, k=\frac{1}{(\ln m)}\right) .
\end{aligned}
$$

(4) Calculate the comprehensive feudatory degree $Z_{i}$ of each evaluation object:

$$
\begin{gathered}
\omega_{j}=\frac{1-H_{j}}{n-\sum_{j=1}^{n} H_{j}}, \\
Z_{i}=\left(r_{i j}\right)_{m \times n} \omega^{T} .
\end{gathered}
$$

\begin{tabular}{|c|c|c|c|c|c|c|c|c|c|c|c|c|}
\hline \multirow{2}{*}{$\begin{array}{l}\text { Schemes } \\
\text { Risk degree } \\
\text { indexes }\end{array}$} & \multicolumn{3}{|c|}{ Scheme 1} & \multicolumn{3}{|c|}{ Scheme 2} & \multicolumn{3}{|c|}{ Scheme 3} & \multicolumn{3}{|c|}{ Scheme 4} \\
\hline & $M$ & $P$ & $F$ & $M$ & $P$ & $F$ & $M$ & $P$ & $F$ & $M$ & $P$ & F \\
\hline$S_{11}$ & 5 & 8 & 3 & 8 & 5 & 5 & 6 & 5 & 3 & 1 & 5 & 3 \\
\hline$S_{12}$ & 8 & 3 & 2 & 4 & 1 & 7 & 5 & 8 & 2 & 5 & 7 & 2 \\
\hline$S_{13}$ & 6 & 1 & 5 & 8 & 6 & 3 & 4 & 4 & 3 & 2 & 8 & 3 \\
\hline$S_{14}$ & 8 & 1 & 1 & 7 & 6 & 4 & 8 & 4 & 2 & 9 & 2 & 3 \\
\hline$S_{15}$ & 2 & 6 & 3 & 6 & 3 & 9 & 3 & 7 & 6 & 6 & 8 & 5 \\
\hline$S_{16}$ & 5 & 4 & 5 & 4 & 3 & 3 & 1 & 5 & 7 & 7 & 3 & 1 \\
\hline$S_{17}$ & 5 & 6 & 7 & 5 & 3 & 3 & 2 & 5 & 2 & 1 & 5 & 8 \\
\hline$S_{18}$ & 5 & 5 & 9 & 7 & 6 & 4 & 4 & 7 & 7 & 5 & 5 & 5 \\
\hline$S_{19}$ & 5 & 7 & 7 & 8 & 3 & 8 & 7 & 4 & 5 & 1 & 8 & 6 \\
\hline$S_{21}$ & 6 & 5 & 4 & 5 & 2 & 3 & 5 & 6 & 5 & 3 & 7 & 9 \\
\hline$S_{22}$ & 8 & 6 & 2 & 2 & 9 & 1 & 1 & 3 & 1 & 5 & 3 & 8 \\
\hline$S_{23}$ & 8 & 9 & 4 & 9 & 4 & 7 & 4 & 1 & 9 & 5 & 8 & 4 \\
\hline$S_{24}$ & 8 & 6 & 5 & 2 & 1 & 5 & 4 & 9 & 4 & 9 & 1 & 9 \\
\hline$S_{25}$ & 2 & 8 & 4 & 8 & 7 & 2 & 8 & 8 & 4 & 8 & 1 & 3 \\
\hline$S_{26}$ & 6 & 6 & 1 & 9 & 7 & 2 & 3 & 7 & 6 & 8 & 6 & 3 \\
\hline$S_{31}$ & 5 & 8 & 3 & 8 & 5 & 4 & 2 & 6 & 8 & 3 & 4 & 9 \\
\hline$S_{32}$ & 5 & 6 & 3 & 8 & 3 & 7 & 6 & 7 & 2 & 9 & 7 & 7 \\
\hline$S_{33}$ & 5 & 8 & 1 & 6 & 2 & 1 & 5 & 4 & 9 & 2 & 8 & 9 \\
\hline$S_{34}$ & 1 & 3 & 8 & 7 & 2 & 8 & 6 & 8 & 2 & 2 & 1 & 5 \\
\hline$S_{35}$ & 8 & 3 & 2 & 2 & 3 & 6 & 5 & 6 & 9 & 7 & 4 & 9 \\
\hline$S_{36}$ & 1 & 5 & 9 & 8 & 3 & 2 & 1 & 2 & 5 & 7 & 7 & 8 \\
\hline$S_{37}$ & 6 & 7 & 7 & 3 & 1 & 2 & 5 & 5 & 8 & 8 & 5 & 4 \\
\hline
\end{tabular}

TABLE 9: The calculated safety score value of 4 building construction schemes.

TABLE 10: The calculated total value of 4 indexes including cost, progress, quality, and safety of 4 building construction schemes.

\begin{tabular}{lcccc}
\hline & Cost & Progress & Quality & Safety \\
\hline Scheme 1 & 306.58 & 0.192 & 0.233 & 2527.00 \\
Scheme 2 & 308.96 & 0.173 & 0.291 & 2233.00 \\
Scheme 3 & 291.40 & 0.203 & 0.368 & 2450.00 \\
Scheme 4 & 304.33 & 0.172 & 0.260 & 2886.00 \\
\hline
\end{tabular}

6.3. Calculations Combined with Case. Standardizes evaluation index matrix composed of value in Table 10. Cost and safety indexes are ones that is "the smaller, the better", making use of a formula (11) to calculate. Progress and quality indexes are ones that is "the bigger, the better", making use of a formula (10) to calculate. The standardization result is shown in Table 11".

Making use of formula (12) and (13) to calculate the entropy value and entropy weight of 4 schemes, the result is shown in Table 12. 
TABLE 11: The standardization result of 4 building construction schemes based on 4 decision indexes.

\begin{tabular}{lcccc}
\hline & Cost & Progress & Quality & Safety \\
\hline Scheme 1 & 0.136 & 0.645 & 0.001 & 0.55 \\
Scheme 2 & 0.001 & 0.032 & 0.430 & 1.00 \\
Scheme 3 & 1.000 & 1.000 & 1.000 & 0.67 \\
Scheme 4 & 0.264 & 0.001 & 0.200 & 0.01 \\
\hline
\end{tabular}

TABLE 12: The calculated entropy value and entropy weight of 4 schemes.

\begin{tabular}{lcccc}
\hline Indexes & Cost & Progress & Quality & Safety \\
\hline Entropy value $\left(H_{i}\right)$ & 0.678 & 0.567 & 0.873 & 0.413 \\
Entropy weighs $\left(\omega_{i}\right)$ & 0.219 & 0.295 & 0.087 & 0.400 \\
\hline
\end{tabular}

Calculates comprehensive feudatory degree $Z_{i}$ of each evaluation scheme by formula (14) are shown as follows:

$$
\begin{aligned}
Z_{i} & =\left(r_{i j}\right)_{m \times m} \omega^{T} \\
& =\left[\begin{array}{llll}
0.136 & 0.645 & 0.001 & 0.55 \\
0.001 & 0.032 & 0.430 & 1.00 \\
1.000 & 1.000 & 1.000 & 0.67 \\
0.264 & 0.001 & 0.200 & 0.01
\end{array}\right]\left[\begin{array}{l}
0.219 \\
0.295 \\
0.087 \\
0.400
\end{array}\right] \\
& =[0.440,0.447,0.869,0.080] .
\end{aligned}
$$

\section{Conclusions}

Based on the above calculation results, 4 building construction project schemes can be selected according to such sequence: Scheme $3>$ Scheme $2>$ Scheme $1>$ Scheme 4 . Generally, the optimization decision of building construction schemes is usually multiobjective optimization decisionmaking problem affected by many factors. This paper selects cost, progress, quality, safety as the four first-order evaluation indexes, and further deployment analyses of these indexes integrate engineering economics, risk and reliability theories, and information entropy theory to present a new evaluation optimization method for building construction projects based on integrated information entropy with the reliability theory combined with a case study. Presented detailed methods and steps can offer the reference for engineering management decision for the building construction projects.

\section{Acknowledgments}

This work was supported in part by NSFC (59874019), Shanxi Province Education Department Research Project (12JK0803), Shanxi Province Key Discipline Construction Special Fund Subsidized Project (E08001), Shanxi Province Higher Education Philosophical Social Science Key Research Base Construction Special Fund Subsidized Project (DA08046), and Shanxi Province Higher Education Philosophical Social Science Characteristic Discipline Construction Special Fund Subsidized Project (E08003, E08005).

\section{References}

[1] Y. Xu, Y. Wang, and B. Yao, "Construction project stakeholder collaboration group decision making based on entropy theory," Chinese Journal of Management Science, vol. 16, pp. 117-121, 2008.

[2] Y. Feng and K. Shi, "Optimum decision-making of deep foundation pit construction project based on the least variance priority method," Building Science, vol. 25, no. 1, pp. 12-15, 2009.

[3] B. Tian, Management Science in Engineering Project, Southwest Jiaotong University Press, 2009.

[4] Y. Chen and X. Peng, "Method of analytical hierarchy process making for decision on construction scheme," Journal of Zhengzhou University of Light Industry (Natural Science), vol. 22, pp. 198-200, 2007.

[5] J. Chen, "On construction scheme selected based on value engineering," Shanxi Architecture, vol. 12, no. 36, p. 202, 2010.

[6] S. Gao and H. Du, "Study on comprehensive evaluation method about engineering construction scheme based on Grey Correlation Degree," Coal Mine Engineering, no. 1, pp. 37-39, 2003.

[7] Y. Feng, "Optimum decision-making of construction project based on the least variance priority method," Mathematics in Practice and Theory, vol. 36, no. 3, pp. 171-173, 2006.

[8] W. Oiu, Management Decision and Application Entropy, Mechanical Industry Press, 2001.

[9] J. Wang and E. Liu, "Analysis of time-cost-quality tradeoff optimization in construction project management," Journal of Systems Engineering, vol. 19, no. 2, pp. 148-150, 2004.

[10] J. Touboul, "Projection pursuit through relative entropy minimization," Communications in Statistics, vol. 40, no. 6, pp. 854878, 2011.

[11] Q. Liu and Q. Yang, "The control of cost, duration, 'quality and safety in project management of construction," Journal of Ningxia Institute of Technology (Natural Science), vol. 9, no. 1, pp. 31-33, 1997.

[12] N. Lu, Y. Shi, X. Gao, W. Li, and X. Liao, "Calculation method of construction working procedure," Journal of Xian University of Architecture \& Technology (Natural Science Edition), vol. 38, no. 3, pp. 311-315, 2006.

[13] W. Qiu, "An entropy model on group decision system," Control and Decision, vol. 10, no. 1, pp. 51-53, 1995.

[14] L. Ma and Q. Gao, "Analysis of organizational structure for human resource management department based on structureentropy model," Industrial Engineering Journal, no. 4, pp. 86-90, 2010.

[15] Z. Turskis, M. Gajzler, and A. Dziadosz, "Reliability, risk management, and contingency of construction processes and projects," Journal of Civil Engineering and Management, vol. 18, no. 2, pp. 290-298, 2012.

[16] J. Oh, H. Kim, and D. Park, "Bi-objective network optimization for spatial and temporal coordination of multiple highway construction projects," KSCE Journal of Civil Engineering, vol. 15, no. 8, pp. 1449-1455, 2011. 

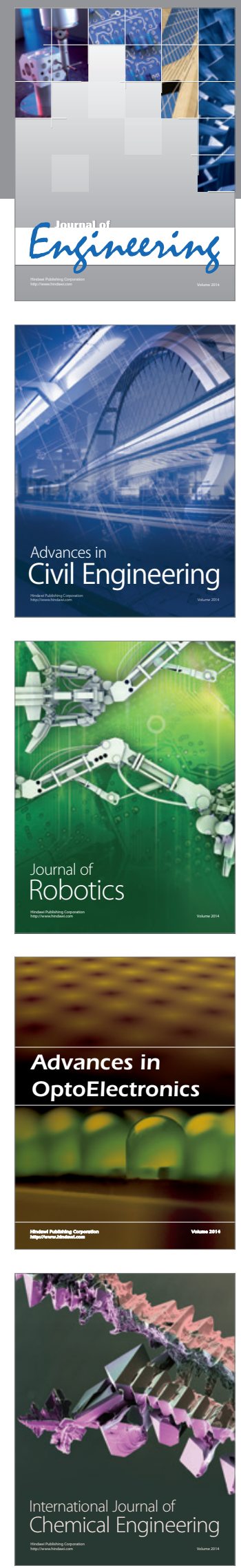

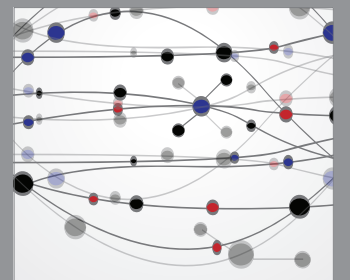

The Scientific World Journal
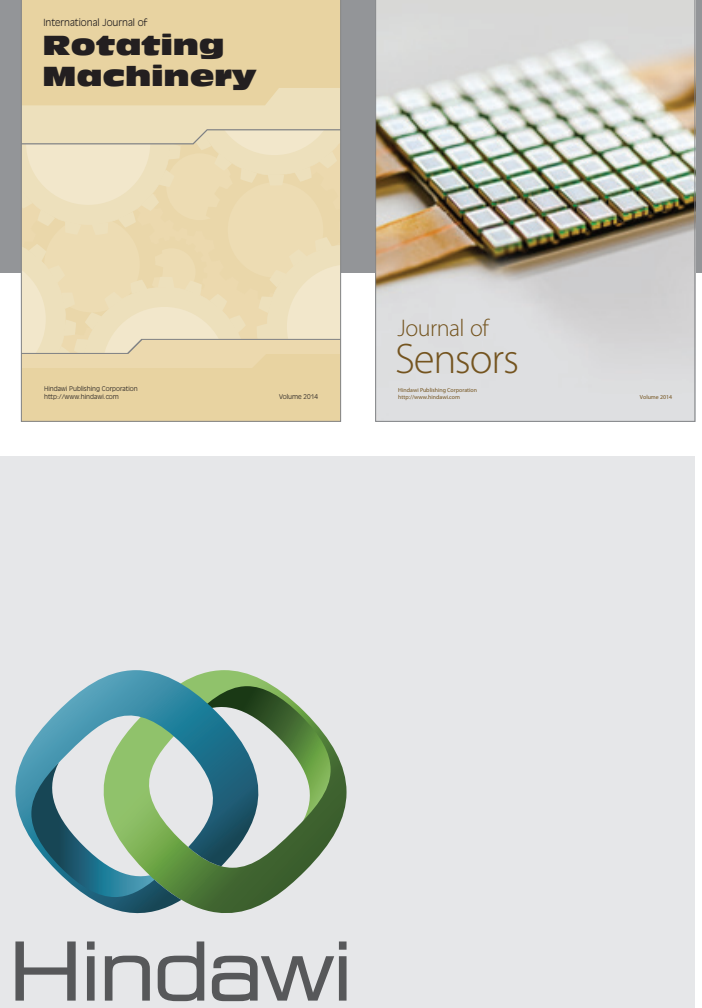

Submit your manuscripts at http://www.hindawi.com
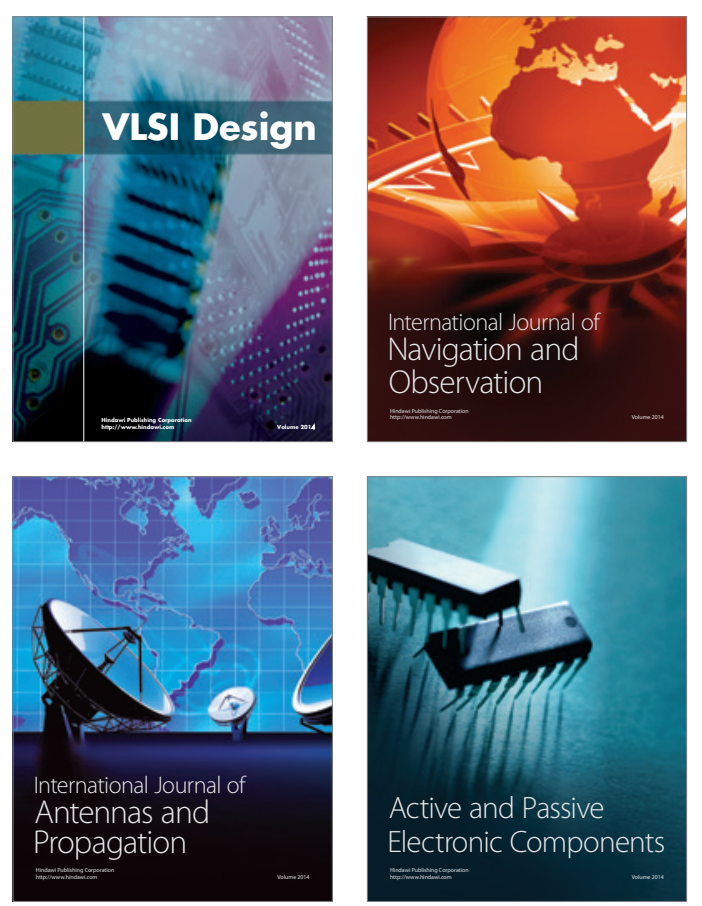
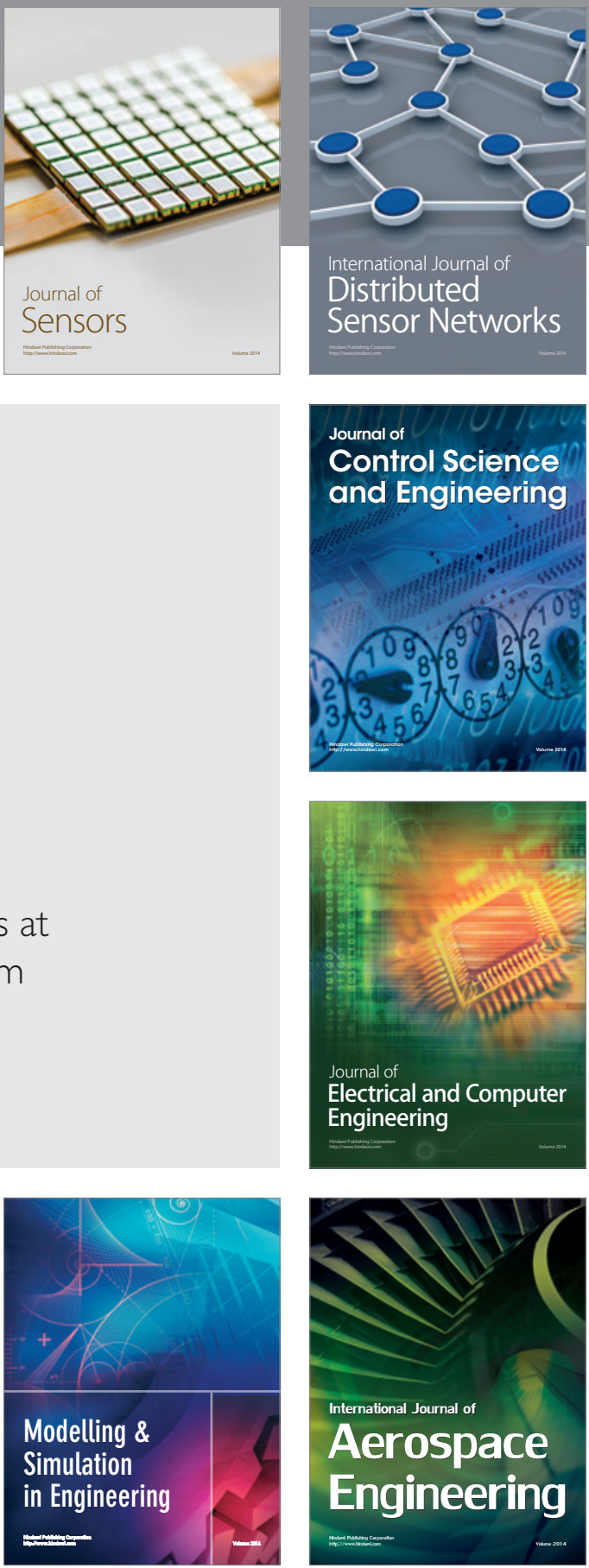

Journal of

Control Science

and Engineering
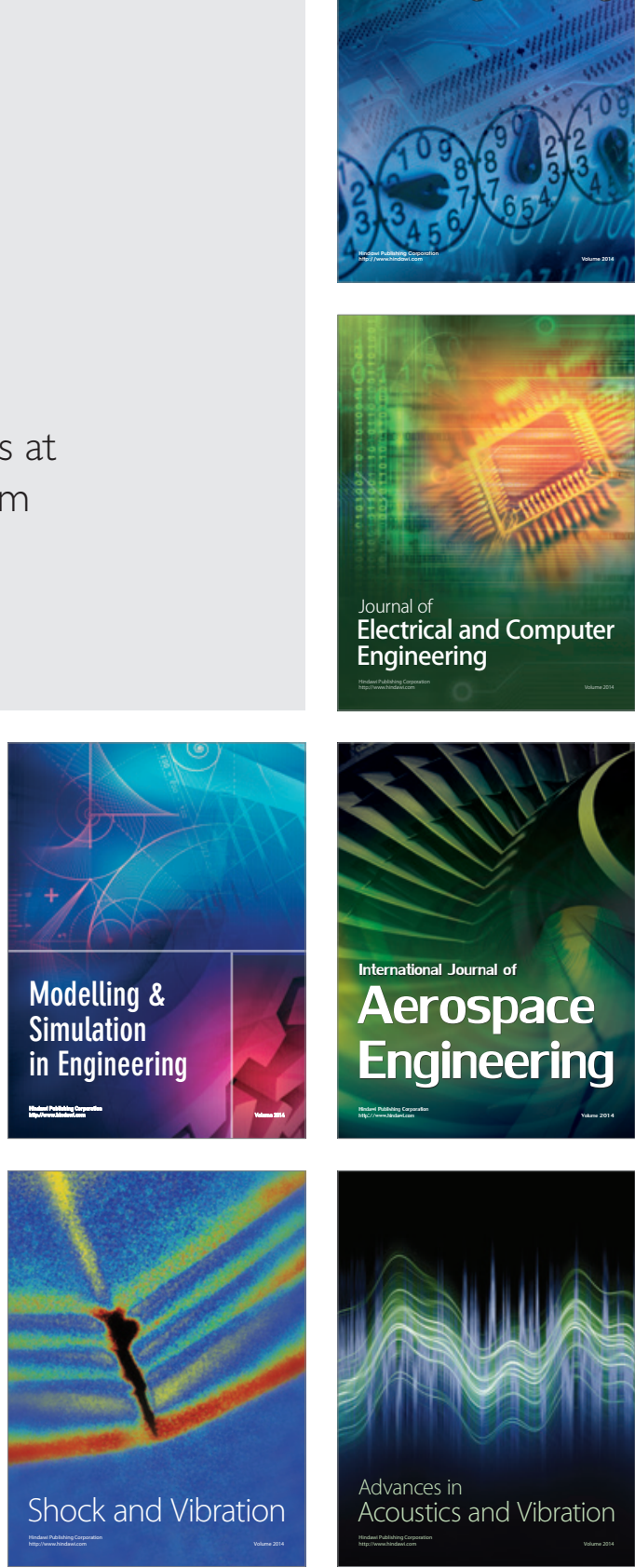